\section{SAÚDE E AMBIENTE}

V.7 $\cdot$ N.3 $\cdot$ Abril -2019

ISSN Digital: 2316-3798

ISSN Impresso: 2316-3313

DOI: 10.17564/2316-3798.2019v7n3p9-24 ORCID: 0000-0002-7779-5126

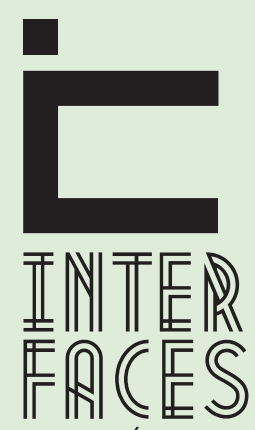

CIENTÍFICAS

\title{
DESGASTE EMOCIONAL DOS ENFERMEIROS COORDENADORES DA ÁREA DE SAÚDE/MG*
}

EMOTIONAL WEAR OF NURSES COORDINATORS OF THE HEALTH AREA/MG

DESGASTE EMOCIONAL DE LOS ENFERMEROS COORDINADORES DEL ÁREA DE SALUD/MG

Alexandre Sylvio Vieira da Costa $^{1}$ Marcio Luiz Silva ${ }^{2}$

* Artigo baseado na dissertação de Mestrado de Márcio Luiz da Silva, intitulada "O Territorio da Atenção Básica: Análise da Síndrome de Burnout nos Enfermeiros coordenadores da Atenção Básica em Teófilo Otoni-MG", defendida em 2014 no Programa de Pós-Graduação em Gestão Integrada de Território da Universidade Vale do Rio Doce.

\section{RESUMO}

Toda prática laboral é pautada por riscos ambientais e pela possibilidade de surgimento de diversas doenças, entre elas o estresse ocupacional. O território da Atenção Básica tem acumulado situações históricas, ambientais e sociais que promovem condições particulares para a ocorrência de doenças. O objetivo principal foi investigar o nível de desgaste emocional e os indicativos que poderiam estar presentes para caracterizar a Síndrome de Burnout dos coordenadores das unidades de Estratégia de Saúde da Família vinculados no município de Teófilo Otoni, no Vale do Mucuri, região Nordeste de Minas Gerais. A metodologia utilizada para o estudo foi do tipo observacional, transversal descritivo junto a todos os dezenove enfermeiros coordenadores das unidades de Estratégia de Saúde da Família da zona urbana do município. Os resultados demonstraram que a sobrecarga de trabalho e o sentimento de impotência de resolução das atividades podem influenciar diretamente no desempenho das suas atividades, afetando até o contato com os pacientes. Em relação aos limites estabelecidos pelo Núcleo de Estudos Avançados sobre a Síndrome de Burnout (NEPASB), no ponto de corte, verificou-se que 17 dos profissionais apresentaram alta classificação para exaustão emocional, alta classificação de despersonalização e baixa classificação para realização profissional. 0 inventário de Maslach Burnout apresentou percentual de $84,6 \%$, apontando para o risco de desenvolvimento da Síndrome de Burnout. Concluiu-se que existe a necessidade de implementação pelas autoridades responsáveis de ações voltadas para a promoção de um ambiente de trabalho em Teófilo Otoni que diminua os riscos do adoecimento pela atividade laboral. 


\section{PALAVRAS-CHAVE}

Território da Atenção Básica. Burnout. Enfermeiros. Estratégia de Saúde da Família.

\section{ABSTRACT}

All work practices are based on environmental risks and the possibility of several diseases, including occupational stress. The territory of Basic Attention has accumulated historical, environmental and social situations that promote particular conditions for the occurrence of diseases. The main objective of this dissertation was to investigate the level of emotional exhaustion and indicatives that could be present to characterize the Burnout Syndrome of the coordinators of the Family Health Strategy units linked in the municipality of Teófilo Otoni, in the Mucuri Valley, in the Northeastern region of Minas Gerais. The methodology used for the study was an observational, descriptive cross - sectional study with all nineteen coordinating nurses of the Family Health Strategy units of the urban area of the municipality. The results showed that the work overload and the feeling of impotence of resolution of the activities can directly influence the performance of their activities, affecting even the contact with the patients. In relation to the limits established by the NEPASB, at the cut-off point, it was verified that 17 of the professionals presented high classification for emotional exhaustion, high classification of depersonalization and low classification for professional accomplishment. The inventory of Maslach Burnout presented a percentage of $84.6 \%$, pointing to the risk of developing Burnout Syndrome. It was concluded that there is a need for implementation by the responsible authorities of actions aimed at promoting a work environment in Teófilo Otoni that reduces the risks of illness due to work activity.

\section{KEYWORDS}

Territory of Basic Attention. Burnout. Nurses. Family Health Strategy.

\section{RESUMEN}

Toda práctica laboral es pautada por riesgos ambientales y por la posibilidad de surgimiento de diversas enfermedades, entre ellas el estrés ocupacional. El territorio de la Atención Básica ha acumulado situaciones históricas, ambientales y sociales que promueven condiciones particu- 
lares para la ocurrencia de enfermedades. El objetivo principal de este estudio fue investigar el nivel de desgaste emocional y los indicativos que podrían estar presentes para caracterizar el Síndrome de Desgate Profesional de los coordinadores de las unidades de Estrategia de Salud de la Familia vinculados en el municipio de Teófilo Otoni, en el Valle del Mucuri, región nordeste de Minas Gerais. La metodología utilizada para el estudio fue del tipo observacional, transversal descriptivo junto a todos los diecinueve enfermeros coordinadores de las unidades de Estrategia de Salud de la Familia de la zona urbana del municipio. Los resultados demostraron que la sobrecarga de trabajo y el sentimiento de impotencia de resolución de las actividades pueden influenciar directamente en el desempeño de sus actividades, afectando incluso el contacto con los pacientes. En cuanto a los límites establecidos por el NEPASB, en el punto de corte, se verificó que 17 de los profesionales presentaron alta clasificación para agotamiento emocional, alta clasificación de despersonalización y baja clasificación para realización profesional. El Inventario de Maslach Burnout presentó un porcentaje del 84,6\%, apuntando al riesgo de desarrollo del Síndrome de Desgaste Profesional. Se concluyó que existe la necesidad de implementación por las autoridades responsables de acciones dirigidas a la promoción de un ambiente de trabajo en Teófilo Otoni que disminuya los riesgos de la enfermedad por la actividad laboral.

\section{PALABRAS CLAVE}

Territorio de la Atención Básica. Burnout. Enfermeros. Estrategia de salud de la familia.

\section{INTRODUÇ̄̃O}

Os diversos aspectos que constituem a identidade do indivíduo e que se apresenta de grande significância é o trabalho e suas relações. Alguns autores identificam que um dos caminhos encontrados pelo homem para satisfação de seus desejos é o trabalho, elemento essencial em sua qualidade de vida (ALVES, 2013).

Segundo Markus e Lisboa (2015), o trabalho pode ser identificado pelo indivíduo na sua realização pessoal e no prazer da atividade, duas condições importantes da vida humana. Atuar na área de identificação profissional abre espaço para o desenvolvimento psicossocial do homem, conferindo-lhe uma identidade, culminando com uma grande sensação de prazer, segundo Silva e Silva (2015).

Os programas de saúde, que aproximam o profissional dos indivíduos e seus grupos, bem como a sua comunidade, têm se tornado um marco no setor saúde, por facilitar ações de promoção da saúde que geram grandes impactos orçamentários no financiamento desse setor. Nesse sentido, os cuidados primários à saúde, por meio da Estratégia de Saúde da Família (ESF), programa de governo 
criado em 1994, trazem a proposta de desenvolver um modelo de atenção e de vigilância calcado nos princípios de estabelecimento de vínculos e corresponsabilização entre profissionais de saúde e a população (BRASIL, 1997).

As condições impostas no ambiente de trabalho e a exigência do aumento de produtividade são fatores comuns nos dias atuais em todas as classes profissionais. Em relação ao profissional enfermeiro, essas exigências somadas às relações de poder entre a equipe, além das condições insalubres do seu trabalho, submetem este profissional a situações de contínuo estresse. Guimarães e Grubits (1999) revelaram que as condições do ambiente de trabalho, tais como o espaço físico, a ergonomia do local, a pressão psicológica, a falta de equipamentos, escassez de medicamentos e a própria atividade ocupacional podem afetar a qualidade do atendimento no trabalho.

Autores, como Pitta (2003), estudaram a respeito da existência de diversos estressores no universo de trabalho do enfermeiro e evidenciou, nesse meio, o sofrimento psíquico, juntamente com a dor pela morte. Corroborando com esse pensamento, Stacciarini e Tróccoli (2001) demonstraram que o estresse do enfermeiro é uma realidade, contudo, não chegaram às respostas quanto à existência ou não de outra função ocupacional mais estressante. Não obstante, esses mesmos autores observaram que as fontes de estresse se diferenciam, dependendo da função e ou setor de trabalho.

O profissional enfermeiro no modelo organizacional da Estratégia de Saúde da Família (ESF) assume o papel na maioria das unidades como coordenador do serviço, sendo esse modelo assumido pelo município de Teófilo Otoni/MG. Peduzzi e Anselmi (2002) descrevem esse profissional, como sendo aquele que na maioria das vezes encontra-se comprometido com o gerenciamento do cuidado e da unidade.

Nesse sentido, o estresse ocupacional dos profissionais de enfermagem merece atenção, uma vez que vivenciam tanto uma carga emocional diante da relação com o paciente, como as responsabilidades de intensa sobrecarga de trabalho. A questão tem sido associada a sensações de desconforto, sendo cada vez maior o número de pessoas que se definem estressadas ou que relacionam a outros indivíduos com a mesma situação (STACCIRINI; TROCCOLI, 2001).

Segundo Benevides (2004), a Síndrome de Burnout sobrevém de um processo de estresse ocupacional que rompe o equilíbrio psicofisiológico do indivíduo, obrigando-o a utilizar-se de recursos extras de energia, em ações desnecessárias ou incompatíveis com as estratégias de enfrentamento desencadeadoras deste contexto. Dependendo da intensidade e do tempo de ocorrência desse processo, o indivíduo pode vir a sofrer consequências graves, tanto no nível físico como psicológico. Os sintomas dessa síndrome se dividem em quatro grupos: físicos; comportamentais; psíquicos e defensivos.

Para Teixeira (2011), a primeira medida para evitar o surgimento da Síndrome de Burnout é conhecer as suas manifestações, e para tal, é preciso que os profissionais de enfermagem adquiram conhecimentos relacionados, sendo também necessário que as organizações de saúde implementem medidas de prevenção e tratamento, em nível individual, grupal e organizacional. 
Feliciano e outros autores (2005) mostraram na sua pesquisa que, nos últimos anos, houve uma grande distribuição mundial desta síndrome entre médicos e enfermeiras, com altos níveis de exaustão emocional, despersonalização e falta de realização pessoal.

A perspectiva é que cada profissional tenha sua percepção quanto ao ambiente organizacional. Nesse aspecto, o desgaste emocional irá depender dos eventos ocorridos e avaliados como estressores, podendo ser causadores desse conflito. Desse modo, ao se questionar quanto à relação laboral dos enfermeiros coordenadores e a possibilidade de desenvolvimento da Síndrome de Burnout, o resultado dos estudos poderá subsidiar os gestores de saúde, na implantação de políticas, que visem à prevenção e minimização dos fatores desencadeante para o adoecimento do trabalho.

\section{MÉTODOS}

Este estudo teve caráter observacional descritivo, visando analisar, registrar e interpretar os fatos, sem que esse sofra interveniências do pesquisador. Segundo Szklo e Javier Nieto (2000), em especial, no âmbito da saúde, o estudo descritivo tem por objetivo determinar a distribuição de doenças ou condições relacionadas à saúde, segundo o tempo, o lugar ou as características dos indivíduos. De acordo com Minayo e Sanches (1993), a pesquisa quantitativa atua em níveis de realidade, o que pode trazer maior clareza dos indicadores. 0 modelo utilizado foi do tipo transversal. Segundo Sampieri e outros autores (2006), o modelo do tipo transversal é apropriado para descrever características das populações, em determinadas variáveis e seus padrões de distribuição.

A pesquisa teve aprovação pelo Comitê de Ética em Pesquisa - CEP/UNIVALE, com número CAAE: 27598814.8.0000.5157.

A pesquisa foi realizada no município de Teófilo Otoni, localizado no Vale do Mucuri, na região Nordeste de Minas Gerais. A população do município de Teófilo Otoni em 2013, segundo o Instituto Brasileiro de Geografia e Estatística (IBGE), constituía-se de 135.745 habitantes, possuindo densidade demográfica de 41,87 habitantes $/ \mathrm{km}^{2}$.

O Município de Teófilo Otoni possui atualmente 33 equipes de saúde, sendo 29 Programas de Estratégia de Saúde da Família e quatro Programas de Agente Comunitário de saúde (PACS).

Todo o espaço urbano do município é subdividido em quatro distritos, que atendem as áreas estratégicas geográficas da população, conforme apresentado na Figura 1. 
Figura 1 - Localização das equipes de saúde na zona urbana de Teófilo Otoni/MG

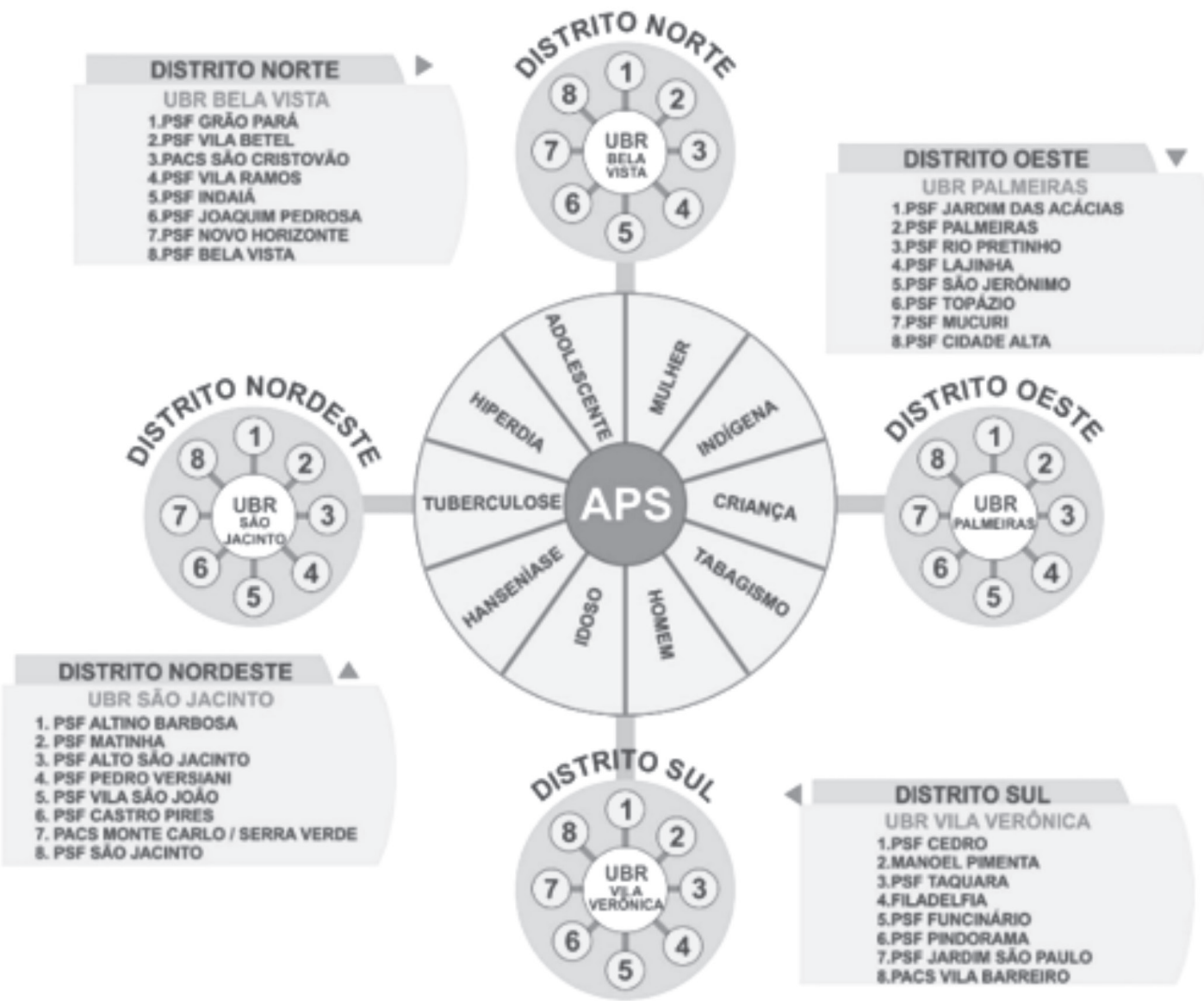

Fonte: Teófilo Otoni (2013).

A escolha dos enfermeiros da Estratégia de Saúde da Família deve-se pelo fato destes profissionais ficarem diante de situações conflituosas que podem gerar o estresse com sobrecarga psíquica e exaustão emocional, tendo em vista que lidam com a coordenação das unidades de saúde, organização e gerenciamento das atividades que são desenvolvidas.

Os sujeitos elegíveis para o estudo foram enfermeiros coordenadores atuantes na ESF, localizadas na zona urbana, que aceitaram participar voluntariamente da pesquisa. Estes profissionais foram abordados coletivamente em reunião após o workshop e sem a participação das supervisões. Todos foram orientados sobre o objetivo e a metodologia para o preenchimento do inventário e a evitar o diálogo entre os pares para impedir possíveis induções nas respostas. 0 número de enfermeiros elegíveis foram 19 (100\% dos coordenadores), recebendo a pesquisa. 
Como instrumento de coleta de dados, foi utilizado: o Inventário de Maslach Burnout(MBI). Trata-se de um questionário utilizado para estimar a Síndrome de Burnout, composto por afirmações sobre sentimentos e atitudes, que engloba os três aspectos fundamentais da síndrome - exaustão emocional, despersonalização e envolvimento pessoal no trabalho. É composto por 22 questionamentos, sendo nove para a dimensão de exaustão emocional, cinco para despersonalização e oito para realização pessoal. Para cada questão, as opções de resposta foram em likert, variando de 0 a 6 onde: 0 refere-se a "nunca", 1 se refere a "uma vez por ano ou menos", 2 a “uma vez por mês menos", 3 a "algumas vezes por mês", 4 a "uma vez por semana”, 5 a "várias vezes por semana” e 6 a "diariamente". Visa a identificar os profissionais enfermeiros com diferentes níveis de exaustão, os quais foram classificados em Esgotados e Não esgotados. Os valores obtidos foram comparados com os valores de referência do Grupo de Estudos e Pesquisas sobre Estresse e Burnout (GEPEB).

Como escore de referência do inventário, têm-se valores superiores ou iguais a 75, nas sub escalas de despersonalização e desgaste emocional, como também os que se enquadram no percentil 25 na sub escala de realização profissional. Com o intuito de contribuir para o aumento na confiabilidade das respostas, foi aplicado o coeficiente alfa de Cronbach, de acordo com os limites apresentados no Quadro 1, no qual foi possível considerar como satisfatórios os questionários que apresentem valores maiores que 0,60.

Quadro 1 - Valores do coeficiente alfa de Cronbach relacionados ao Inventário Maslach Burnout

\begin{tabular}{|c|c|c|c|c|c|}
\hline Confiabilidade & $\begin{array}{c}\text { Muito } \\
\text { Baixa }\end{array}$ & Baixa & Moderada & Alta & Muito Alta \\
\hline Valor de & $\leq 0,30$ & $0,30<\leq 0,60$ & $0,60<\leq 0,75$ & $0,75<\leq 0,90$ & $>0,90$ \\
\hline
\end{tabular}

Fonte: Adaptado de Molina e outros autores (2013).

Os dados foram analisados no programa estatístico SAEG da Universidade Federal de Viçosa, com emprego de análises descritivas de correlação de Pearson variando de -1 até +1 . Foi utilizado o valor de probabilidade de $5 \%$ e $1 \%(\mathrm{P}<0,05$ e $\mathrm{P}<0,01)$ e intervalo de confiança de $95 \%$.

\section{RESULTADOS}

A primeira questão com o objetivo de avaliar a exaustão emocional foi se, ao final de um dia de trabalho, o profissional se sentia esgotado. Grande parte dos enfermeiros (52\%) manifestou ter algumas vezes, ao decorrer do mês, a sensação de esgotamento ao final de um dia de trabalho. Os demais, Apesar de em proporções menores, também se queixaram desse esgotamento. Os dados obtidos corroboram com as informações descritas por Simões e Bianchi (2016) onde observaram que, dos profissionais de saúde avaliados, 59,5\% apresentaram cansaço ou esgotamento frequente com $48,9 \%$ apresentando dificuldades para dormir. 
A exaustão emocional é caracterizada por fadiga intensa, falta de força para enfrentar o dia de trabalho e a sensação de estar sendo exigido além de seus limites emocionais. Esta dimensão está contemplada em nove questões do inventário de Maslach, sendo as seguintes afirmativas: sinto-me esgotado ao final de um dia de trabalho; sinto como se estivesse no meu limite; sinto-me emocionalmente exausto com o meu trabalho; sinto estar trabalhando demais no emprego; trabalhar o dia todo com pessoas exige um grande esforço; sinto que influencio positivamente a vida dos outros com meu trabalho; lido de forma adequada com os problemas do paciente; sinto que posso tratar de forma tranquila os problemas emocionais do trabalho e tenho me tornado mais insensível com as pessoas, desde que exerço este trabalho.

Os resultados deste inquérito para as novas questões tiveram, como pontuação máxima, o percentual de $52 \%$ para o item algumas vezes ao mês, $21 \%$ uma vez por semana, $12 \%$ várias vezes por semana e de $5 \%$ para os itens uma vez ao ano ou menos.

A segunda dimensão caracteriza a despersonalização, sendo avaliados o distanciamento emocional e a indiferença em relação ao trabalho ou aos seus clientes. Normalmente, esse nível expressa cinismo ou agressão. A diminuição do envolvimento pessoal no trabalho também é caracterizada como falta de perspectivas para o futuro, frustração e sentimentos de incompetência e fracasso. As questões no inventário, que contemplam esta dimensão, totalizam cinco: sinto que estou esgotado com o trabalho; sensação de estar cheio de energia; sensação de estar estimulado depois de trabalhar com os pacientes; entendo com facilidade o que sentem os pacientes; preocupa-me que este trabalho esteja me endurecendo emocionalmente.

0 critério para marcação das respostas é o utilizado na exaustão emocional. Os resultados foram de $71 \%$ para a opção nunca. As opções, uma vez ao ano ou menos e várias vezes por semana, totalizaram 5\%; a opção uma vez ao mês ou menos totalizou $10 \%$ e algumas vezes ao mês $9 \%$.

A realização profissional, caracterizada como a terceira dimensão da Síndrome de Burnout, é composta de oito perguntas, que seguem o padrão de resposta das dimensões anteriores. As questões do inventário que contemplam essa dimensão são: sensação de estar frustado com o trabalho; o trabalho direto com pessoas me deixa muito estressado(a); sinto-me cansado(a) quando me levanto pela manhã e tenho que encarar outro dia de trabalho; sinto poder criar um ambiente tranquilo para os pacientes; tenho conseguido muitas realizações com minha profissão; sinto que os pacientes me culpam por alguns de seus problemas; sinto que trato alguns pacientes como se fossem objetos e não me preocupo realmente com o que ocorre com meus pacientes.

Assim como na exaustão emocional e despersonalização, os resultados obtidos nesta dimensão de realização profissional foram iguais em todas as oito perguntas. As respostas totalizaram: $71 \%$ para nunca, $10 \%$ para uma vez ao mês ou menos e $9 \%$ algumas vezes ao mês ou menos, $5 \%$ para uma vez ao ano ou menos e várias vezes por semana. As opções, uma vez por semana e diariamente, não foram sinalizadas.

O coeficiente alfa de Cronbach do Inventário de Maslach Burnout aplicado foi de 0,74 considerado satisfatório, com confiabilidade interna moderada.

Houve significância estatística na primeira dimensão (exaustão emocional), quando se buscava correlacionar o nível de esgotamento com as variáveis de exaustão e limite do trabalho. Também foi encontrada cor- 
relação significativa para exaustão no trabalho e influência na vida das pessoas (TABELA 1). As correlações se mostraram altamente positivas, com uma exceção, indicando que os fatores de estresse de exaustão emocional estão associados. 0 esgotamento está associado à exaustão da atividade, muitas horas de trabalho em excesso e no limite do emocional. A correlação negativa indica que estando emocionalmente afetados, o seu comportamento com os pacientes, colegas de trabalho e até familiar são afetados de forma negativa.

Tabela 1 - Coeficiente de Correlação de Pearson das dimensões avaliadas nos enfermeiros coordenadores atuantes na Estratégia de Saúde da Família, Teófilo Otoni, MG, 2013.

\begin{tabular}{|c|c|c|}
\hline \multicolumn{2}{|c|}{ Exaustão Emocional } & Correlação \\
\hline \multirow{3}{*}{$\begin{array}{l}\text { Sinto-me esgotado(a) ao final de } \\
\text { um dia de trabalho }\end{array}$} & Sinto-me como se estivesse no meu limite & $0,5371^{* *}$ \\
\hline & $\begin{array}{l}\text { Sinto-me emocionalmente exausto com } \\
\text { meu trabalho }\end{array}$ & $0,6716^{* *}$ \\
\hline & $\begin{array}{l}\text { Sinto que estou trabalhando } \\
\text { demais neste emprego }\end{array}$ & $0,6082^{* *}$ \\
\hline $\begin{array}{l}\text { Sinto-me como se estivesse no } \\
\text { meu limite }\end{array}$ & $\begin{array}{l}\text { Sinto-me emocionalmente exausto com } \\
\text { meu trabalho }\end{array}$ & $0,5613^{* *}$ \\
\hline $\begin{array}{l}\text { Sinto-me emocionalmente } \\
\text { exausto com meu trabalho }\end{array}$ & $\begin{array}{l}\text { Sinto que influencio positivamente a vida } \\
\text { dos outros com meu trabalho }\end{array}$ & $-0,5353^{* *}$ \\
\hline \multicolumn{3}{|c|}{ Despersonalização } \\
\hline Sinto-me cheio(a) de energia & $\begin{array}{l}\text { Sinto me estimulado (a) depois de } \\
\text { trabalhar em contato com os pacientes }\end{array}$ & $0,7144^{* *}$ \\
\hline
\end{tabular}

Trabalhar diretamente com pessoas me deixa muito estressado

Sinto que trato alguns pacientes como se fossem objetos

** $p<0,01$

Fonte: Dados da Pesquisa
Sinto que os pacientes me culpam por

$0,5662^{* *}$ alguns de seus problemas

Não me preocupo realmente com o que

$0,5669 * *$ ocorre com meus pacientes 
Ao se buscar correlação estatística na segunda dimensão (despersonalização), apenas foi encontrada em uma única questão. "Sinto-me cheio de energia" foi estatisticamente significante com a questão que se refere ao sentimento de estar estimulado depois de trabalhar em contato com os pacientes. A correlação altamente positiva entre os fatores descritos indica que, após o trabalho, os enfermeiros se sentem motivados a qualquer outra atividade fora do trabalho como praticar exercícios e cuidar de seus afazeres pessoais.

Na terceira dimensão, que trata da realização profissional, também houve significância estatística em relação ao sentimento de trabalhar com pessoas e com a sensação de ser culpado pelos pacientes em virtude dos seus problemas. Em todas as dimensões as correlações significativas foram positivas, indicando que as respostas às variáveis analisadas se modificam em uma mesma direção.

O manual do MBI apresenta-se como base para o diagnóstico de Burnout, a obtenção de nível alto para exaustão emocional e despersonalização e nível baixo para realização profissional. Desse modo, a inserção do profissional nessas três dimensões demonstra o problema.

Com relação aos limites estabelecidos pelo Núcleo de Estudos Avançados sobre a Síndrome de Burnout (NEPASB), no ponto de corte, verificou-se que os profissionais pesquisados apresentaram alta classificação para exaustão emocional, despersonalização e baixa classificação para realização profissional. Estes valores são características que estabelecem diagnóstico para manifestação de Burnout. Em relação ao nível de exaustão emocional dos enfermeiros, verificamos que dos 19 enfermeiros entrevistados, a maioria apresentou elevados valores de exaustão, enquanto que nenhum dos profissionais avaliados foram enquadrados na classificação de baixo nível de exaustão emocional (FIGURA 2).

Figura 2 - Nível de exaustão emocional dos enfermeiros coordenadores atuantes na Estratégia de Saúde da Família, de acordo com os limites do Núcleo de Estudos Avançados sobre a Síndrome de Burnout (NEPASB). Teófilo Otoni, MG, 2013

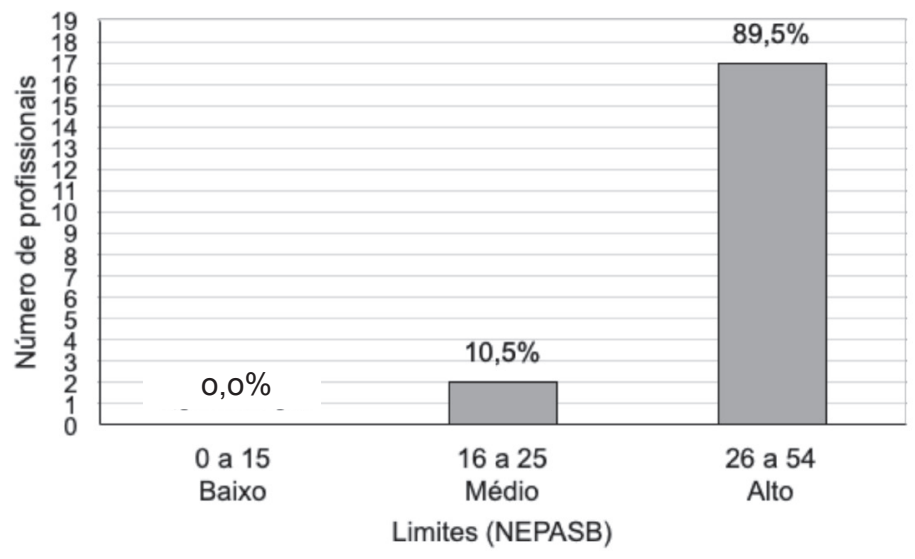

Fonte: Dados da Pesquisa 
Segundo Lorenz e Guirardello (2014), a Síndrome de Burnout ocorre quando o indivíduo percebe não possuir mais condições de despender a energia que o seu trabalho requer. Nesse estado, os profissionais costumam ficar pouco tolerantes e, facilmente, irritáveis no ambiente de trabalho. A despersonalização é considerada uma dimensão típica da Síndrome de Burnout e um elemento no qual se distingue esta síndrome do estresse. Originalmente, apresenta-se como uma maneira do profissional se defender da carga emocional, derivada do contato direto com outro ser humano. Devido a isso, desencadeiam-se atitudes insensíveis em relação às pessoas nas funções que desempenham. Em relação aos enfermeiros avaliados neste estudo, todos os 19 avaliados (100\%), foram classificados com alto nível de despersonalização.

Quanto à redução na realização profissional, este aspecto pode originar-se diante da insatisfação consigo e com o seu trabalho, o que faz surgir sentimentos de incompetência e baixa autoestima, presente em elevados índices na região de Teófilo Otoni. Os resultados demonstram que todos os avaliados (100\%) apresentam um baixo nível de satisfação com a atividade.

\section{DISCUSSÃO}

Os resultados demonstraram percentuais preocupantes, apontando para um número elevado de profissionais enfermeiros, na fase inicial da Síndrome de Burnout, e outros com fortes indícios da possibilidade do adoecimento por esta síndrome em Teófilo Otoni. Ainda nesse contexto, foram verificados, por meio dos dados, altos níveis de exaustão emocional, com apresentação de esgotamento físico e mental. Com altos índices de despersonalização, os enfermeiros revelaram sentimentos de impassibilidade com os pacientes.

Esse resultado coaduna com a descrição de Tibúrcio e Moreno (2009), que afirmaram serem os fatores citados, a representatividade de uma séria ameaça à saúde do profissional e comprometimento de seu trabalho, exigindo intervenção imediata. 0 estresse gerado no ambiente de trabalho é considerado um estado humano desagradável e, segundo Silva e Barros (2015) ocorre em função de externalidades, principalmente de atividades que o ser humano considere comprometedora de sua autoestima e do seu bem-estar.

Guinjoan e Villamisar (2003) entenderam que deve haver o refinamento de estratégias de enfrentamento diante das situações adversas de Síndrome de Burnout, vivenciadas pelos profissionais da enfermagem, com o intuito que se tornem menos vulneráveis. Por outro lado, a Síndrome de Burnout é a resposta desse estresse, que pode estar ligado ao excesso de trabalho, desencadeando alterações comportamentais negativas, afetando consideravelmente pacientes, organização e trabalho (MUROFUSE et al., 2005).

Ainda de acordo com Murofuse e outros autores (2005), a profissão de enfermagem foi classificada pela Health Education Authority como a quarta profissão que produz maior estresse. Gouveia e outros autores (2014), citam que os profissionais da área de enfermagem necessitam de saúde física e mental equilibrada e em boas condições. Mas, apesar deste reconhecimento, verifica-se que os 
profissionais desta área recebem pouco ou nenhum apoio para desempenhar suas atividades diante de sua rotina diária.

Estudos como o de Campos (2005) comprovam que pessoas com maior nível educacional são mais aptas ao Burnout. No presente estudo, com enfermeiros na cidade de Teófilo Otoni/MG, todos apresentam grau educacional elevado, confirmando a afirmativa de Campos onde todos os 19 enfermeiros apresentaram manifestação de Burnout.

Quanto à sobrecarga de trabalho, o sentimento de impotência de resolução das atividades pode influenciar, diretamente, no desempenho da prática laboral, até o contato com os pacientes, como é o caso dos entrevistados deste trabalho. Além disso, no município de Teófilo Otoni, outro ponto, que favorece o desgaste e a exaustão na profissão, está no fato de que a maioria das unidades de saúde assumiu o formato de unidade compartilhada, tendo mais de uma equipe no mesmo espaço. Neste processo, sempre que há uma rotatividade interna ou a substituição de um profissional enfermeiro, para que as atividades não sejam suspensas. Essa atribuição é assumida pelo profissional da equipe que permaneceu no quadro de enfermeiros. Este fato aumenta em muito as atribuições do profissional, impactando diretamente na qualidade da assistência e na sobrecarga de trabalho.

De acordo com a classificação do MBI e a classificação do NEPASB, os 19 profissionais pesquisados apresentam evidências para a Síndrome de Burnout, constatada pela alta prevalência de exaustão emocional (89,4\%), alto grau para despersonalização (100\%) e baixo nível e realização profissional (100\%). Esses resultados estão associados ao alto índice de exaustão emocional e insatisfações em relação às condições de trabalho, potencializadas pela falta de material, pela falta de profissionais e sala de atendimento, dificultando assim a realização das atividades.

Lima e outros autores (2018), avaliando os profissionais da área de saúde da cidade de Juiz de Fora em Minas Gerais, verificaram a prevalência da Síndrome de Burnout em 51\% dos profissionais, com maior destaque para os profissionais da área de enfermagem. Segundo Medeiros e Nóbrega (2013), a capacidade do profissional em lidar com situações estressoras permite identificar a sua vulnerabilidade emocional. Os elementos diários estressantes, mesmo classificados como brandos, podem se tornar acumulativos, gerando riscos à saúde do profissional, comprometendo a sua resistência orgânica.

\section{CONCLUSÃO}

Os resultados sinalizam para a necessidade de implementação, pelas autoridades responsáveis, de medidas urgentes de ações voltadas à saúde desses profissionais na região de Teófilo Otoni em Minas Gerais. Os desafios para a questão do estresse ocupacional e da Síndrome de Burnout não se resumem às condições de trabalho precárias ou ausência de ações voltadas a este campo da saúde do trabalhador, sendo mais ampla e abrangente que coloca os enfermeiros numa condição de não conformidade, em relação ao salário, à exigência de intensa produtividade e não oferecimento de políticas públicas adequadas. 


\section{REFERÊNCIAS}

ALVES, E. F. Qualidade de vida do cuidador de enfermagem e sua relação com o cuidar. Rev Bras Prom Saúde, v. 26, n. 1, p. 36-44, 2013.

BENEVIDES, A. M. A Síndrome de Burnout. In: Congresso Internacional Sobre Saúde Mental no Trabalho, 1., 2004. Anais [...]. Goiânia, Brasil, 2004.

BRASIL. Ministério da Saúde. Secretaria de Assistência à Saúde. Saúde da Família: uma estratégia para reorientação do modelo assistencial. Brasília: MS, 1997.

CAMPOS, R. G. Burnout: uma revisão integrativa na enfermagem oncológica. 2005. $158 f$. Dissertação (Mestrado) - Universidade de São Paulo, Ribeirão Preto, 2005.

FELICIANO, K. V. O. et al. Sentimentos de profissionais de serviços de pronto-socorro pediátrico: reflexões sobre Burnout. Rev Bras Saúde Mat Inf, v. 5, n. 3, p. 319-328, 2005.

GOUVÊA, P. B. et al. Manifestações psicossomáticas associadas à síndrome de Burnout referidas por trabalhadores da saúde. Saúde, v. 40, n. 1, p. 45-52, 2014.

GUIMARÃES, L. A.; GRUBITS, S. Série saúde mental e trabalho. São Paulo: Casa do Psicólogo, 1999.

GUINJOAN, T. F.; VILLAMISAR, D. A. G. El estrés de los profesores: actualización psicológica de um viejo problema. In: Guinjoan, T. F.; Villamisar, D. A. G. (ed.). El estrés del professorado: una perspectiva internacional. Valencia: Promolibro. p. 19-37, 2003.

LIMA, A. S. et al. Análise da prevalência da Síndrome de Burnout em profissionais da atenção básica de saúde. Trab Educ Saúde, v. 16, n. 1, p. 283-304, 2018.

LORENZ, V. R.; GUIRARDELLO, E. B. The environment of professional practice and Burnout in nurses in primary healthcare. Rev Latino-Am Enfermagem, v. 22, n. 6, p. 926-933, 2014.

MARKUS, P. M. N.; LISBOA, C. S. M. Mindfulness e seus benefícios nas atividades de trabalho e no ambiente organizacional. Rev Grad PUCRS, v. 8, n. 1, p. 1-15, 2015.

MEDEIROS, A. J. S.; NÓBREGA, M. M. O estresse entre profissionais de enfermagem nas unidades de atendimento de urgência e emergência: uma revisão de literatura. Rev Bras Educ Saúde, v. 3, n. 3, p. 53-57, 2013. 
MINAYO, M. C. S.; SANCHES, O. Quantitativo-qualitativo: oposição ou complementaridade? Cad Saúde Públ, v. 9, n. 3, p. 239-262, 1993.

MOLINA, J. A. B. et al. Utilización del alfa de Cronbach para validar la confiabilidad de un instrumento de medición de satisfacción del estudiante en el uso del software Minitab. LACCEI - Latin American and Caribbean Conference for Engineering and Technology (LACCEl'2013), 11. 2013. Annals [...]. Cancun, Mexico, 2013.

MUROFUSE, N. T.; ABRANCHES, S. S.; NAPOLEÃO, A. A. Reflexões sobre Burnout e a relação com a enfermagem. Rev Latino-Am Enfermagem, v. 13, n. 2, p. 255-261, 2005.

PEDUZZI, M.; ANSELMI, M. L. O processo de trabalho de enfermagem: a cisão entre planejamento e execução do cuidado. Rev Bras Enferm, v. 55, n. 4, p. 392-398, 2002.

PITTA, A. M. F. Hospital: dor e morte como ofício. 5.ed. São Paulo: Annablume/Hucitec, 2003.

SAMPIERI, R. H. et al. Metodologia da pesquisa. 3.ed. São Paulo: McGraw-Hill, 2006.

SILVA, D. P.; SILVA, M. N. R. M. O. O trabalhador com estresse e intervenções para o cuidado em saúde. Trab Educ Saúde, v. 13, n. 1, p. 201-214, 2015.

SILVA, M. G.; BARROS, B. P. Percepção de estresse de servidores na Atenção Básica de Saúde de Dourados-MS. Saúde em Redes, v. 1, n. 4, p. 35-52, 2015.

SIMÕES, J.; BIANCHI, L. R. O. Prevalência da Síndrome de Burnout e quantidade do sono em trabalhadores técnicos em enfermagem. Rev Saúde Pesq, v. 9, n. 3, p. 473-481, 2016.

STACCIARINI, J. M. R.; TRÓCCOLI, B. T. O stress na atividade ocupacional do enfermeiro. Rev LatinoAm Enfermagem, v. 9, n. 2, p. 17-25, 2001.

SZKLO, M.; JAVIER NIETO, F. Basic study designs in analytical epidemiology. In: Szklo, M.; Javier Nieto, F. Epidemiology: beyond the basics. Gaithersburg: Aspen Publishers Inc. p. 3-51, 2000.

TEIXEIRA, M. 0 Burnout e os enfermeiros. 2011. Disponível em: <http://br.monografias.com/ trabalhos3/Burnout-enfermeiros/Burnout-enfermeiros.shtml >.

TEÓFILO OTONI. Secretaria Municipal de Saúde - SMS/TO. Relatório de Gestão. 2013. 
TIBÚRCIO, A.; MORENO, C. R. C. Síndrome de Burnout em professores do ensino médio de escolas pertencentes à Gerência Regional de Educação e Inovação (GEREI) do município de Tubarão (SC). Interfacehs Rev Gest Int Saúde Trab

Meio Amb, v. 4, n. 1, p. 13-14, 2009.
Recebido em: 27 de Novembro de 2018 Avaliado em: 10 de Janeiro de 2018 Aceito em: 10 de Janeiro de 2018

\section{哬 y.

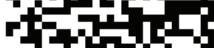 牙:}

A autenticidade desse artigo pode ser conferida no site https://periodicos set.edu.br

\section{Como citar este artigo:}

Costa, Alexandre Sylvio Vieira; Silva, Marcio Luiz. Desgaste emocional dos enfermeiros coordenadores da área de saúde/MG. Interfaces Científicas - Saúde e Ambiente, Aracaju, v. 7, n. 3, p. 9-24, abr. 2019. DOI: 10.17564/2316-3798.2019v7n3p9-24.

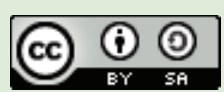

Este artigo é licenciado na modalidade acesso abertosob a Atribuição-Compartilhalgual CC BY-SA

1 Professor Adjunto da Universidade Federal dos Vales do Jequitinhonha e Mucuri, MG, Brasil. Email: asylvio@hotmail.com

2 Mestrado em Gestão Integrada de Território - Universidade Vale do Rio Doce; Secretaria Municipal de Saúde de Porto Seguro, SMS/BA, Brasil. Email: marciosluiz@yahoo.com.br 
